\title{
Patterns and Determinants of Adoption of High Yielding Varieties: Farm-level Evidence from Bangladesh
}

\author{
Mohammad AlAUdDiN and Clem TISDELL*
}

\begin{abstract}
Observations using Bangladeshi survey data tend to support Ahmed's (1981) and Asaduzzaman's (1979) hypothesis postulating an inverse relationship between farm size and intensity of adoption but not Jones' (1984) U-shaped relationship. However, since farm size alone is an inadequate predictor of HYV adoption, bivariate and multivariate techniques including discriminant analysis are used to identify influences on HYV adoption of such variables as subsistence pressure, tenancy, labour scarcity, education, availability of irrigation. Irrigation emerges as the key determinant of HYV adoption.
\end{abstract}

\section{INTRODUCTION}

The bulk of literature on agricultural development in the last two decades is concerned with confirming or denying that the gains from the introduction of the 'Green Revolution' technologies have been unevenly distributed among various groups e.g., large and small producers, producing and non-producing consumers, owner and tenant cultivators. ${ }^{1}$ Much of the argument about the existence of differential gains seems to have resulted from the evidence of differential rates of adoption and diffusion of the new agricultural technology. Hayami and Ruttan (1984 pp. 48-49) after reviewing evidence from a number of Asian countries concluded that ". . . the available evidence indicates that neither farm size nor tenure has been a serious constraint on the MV (modern variety) adoption. . . . On the average, small farmers adopted the MV technology even more rapidly than large farmers". Where evidence to the contrary has been found, it seemed to be "an exception rather than a norm".

*The authors are respectively, Research Scholar, Department of Economics, University of Newcastle, (on leave from Rajshahi University of Bangladesh) and Professor of Economics, University of Newcastle, Australia. Subject to usual caveat they wish to thank an anonynous referee and the editor for useful comments on an earlier draft of the paper. Acknowledgements are also due to Cathy Thirkettle for computational and statistical assistance, and Mohammad Helaluddin, Humayun Kabir and Tarun Sarkar for providing valuable field assistance.

${ }^{1}$ The studies include, among others, those by [Alauddin and Tisdell (1986); Frankel (1971); Griffin (1979); Hayami and Herdt (1977); Hayami and Kikuchi (1981); Hayami and Ruttan (1984, 1985); Lipton (1978); Pearse (1980) and Prahladachar (1983)]. For a stimulating debate in the Pakistani context [see Chaudhry $(1982,1983)$ and Khan $(1983)$. 
A number of recent studies have addressed the question of adoption and diffusion of new agricultural technology in Bangladeshi agriculture. Asaduzzaman (1979); Ahmed (1981); Rahman (1981); Rahman (1983) and Jones (1984) have used farm-level data from different areas of Bangladesh to study the adoption of the HYV (high yielding variety) technology and the factors underlying any emerging pattern. Rahman (1981) using data from Mymensingh and Comilla examined the adoption of HYVs in general in that he did not distinguish between the seasons. (Asaduzzaman 1979) collected data in Rangpur and Noakhali and examined adoption of HYVs in the aman season. The Asaduzzaman (1979) study found that (on operational basis) while higher percentage of larger farmers adopted HYVs, the smaller farmers among the adopters allocated higher percentage of farm area to HYV cultivation. Ahmed (1981) distinguished between two seasons aman and boro and using data from Sylhet, Noakhali and Bogra found (on an ownership basis) that a higher percentage of larger farmers adopted HYVs while the percent area allocated to HYVs among the adopters was negatively associated with farm size. On both counts, owner farmers had higher adoption rates compared to tenant farmers. One of the important factors that determined adoption rate as reported by Ahmed was the extent of irrigation. The village with a higher percentage of area under irrigation was found to be adopting HYVs at a higher rate. Rahman (1983) used data from Dhaka district and emphasized the role of supply-side factors in determining the adoption of HYVs. These included, among other things, the supply of irrigation water and agricultural credit. Furthermore, Rahman (1983) reported an adoption pattern by farm size similar to the one by Ahmed (1981).

Jones (1984), on the other hand, using village level data from the Dhaka district of Bangladesh found some evidence to the contrary. Disaggregating by ownership pattern and season, Jones found a U-shaped adoption pattern. In Jones, study the smallest farmers had the largest proportion of (owner-cultivated) land under HYVs followed by the larger farmers while the medium farmers had the smallest proportion of such land devoted to the new technology. To quote Jones (1984, p. 203), “. . . smaller farmers then are not the slower adopters of HYVs than larger farmers. Rather it is the smallest farmers, ... who are the highest and fastest adopters of the new technology. "Jones, however, notes that the U-shaped relationship is a dynamic one and showed some changes between 1978 and 1980 in that large farmers appeared to be as high adopters as the small farmers if not higher (Jones 1984, Table 10.4). On the question of adoption-share-tenancy relationship, Jones' findings indicate " . . . that the sharecropping system is a serious im. pediment to agricultural development in that both a smaller proportion of share cropped land is cultivated with HYVs and that yields on sharecropped land are significantly lower than those on owner cultivated land" (Jones 1984, p. 209).
While the studies of Bangladesh agriculture referred to above are substantial, they suffer from methodological limitations. While Rahman (1981) and Rahman (1983) provide adequate circumstantial evidence of the various factors underlying differential adoption, they do not carry out further statistical testing to examine the statistical significance of the strength of the causality relationships. Rahman (1981) suffers from further limitation in that HYV adoption is not disaggregated by season. Among other things, the risk factor seems to differ between rainfed and irrigated crops (Ahmed 1981). Jones' study while disaggregating HYV adoption by seasons, does not analyse the factors underlying the observed adoption pattern. Moreover, no further statistical tests are undertaken to provide any adequate explanation of the process of adoption of the HYV technology. Both (Asaduzzaman 1979) and (Ahmed 1981) subject their data to further statistical analysis in order to provide a more in-depth analysis of the adoption process. However, the Asaduzzaman study is concerned only with the rainfed crops and, therefore, leaves no scope for comparison between seasons. The extent to which irrigation, perhaps the most critical factor in the expansion of HYV area helps explain differential adoption rates cannot be ascertained. Ahmed's study is methodologically superior to Asaduzzaman's in this respect. However, (Ahmed 1981) suffers from the limitation that the statistical analysis is carried out in terms of pooled data even though village dummies are employed to account for regional differences. In our view, the process of adoption would have been better highlighted if data were analysed separately for each village. This would have provided a better analytical and comparative basis of within and between village adoption processes.

Apart from the methodological issues discussed above, some of the studies [e.g., Ahmed (1981); Asaduzzaman (1979); Rahman (1981)] employ information which dates back to the early or mid-1970s, while others use data relating to 1978 and 1980 [e.g., Jones (1984); Rahman (1983)]. Some changes have taken place in Bangladesh agriculture since these studies have been completed. For instance, one of the key elements of growth in Bangladeshi food production in the post-Green Revolution period is the increased intensity of cropping. In the last few years this seems to have stabilized just over the 150 percent mark for Bangladesh (Alauddin and Tisdell 1987). In view of this and other changes, new studies employing more recent data are warranted.

Against this background, the objective of this paper is to examine the adoption of HYV technology in Bangladesh employing farm-level data from two Bangladeshi villages. We proceed first of all with a description of the survey areas and survey method. Observed pattern of adoption for a single year (1985-86) is then presented. This is followed by an analysis of the factors underlying the observed pattern of adoption. Both bivariate and multivariate analysis is carried out employing parametric and non-parametric analysis. Among the parametric techniques, apart from 
regression analysis, we use logit and discriminant analysis. The non-parametric techniques include chi-square and $F$ tests. Separate analyses are carried out for each village and then compared to see if there is any difference in the observed pattern and underlying factors.

\section{ADOPTION OF HYV TECHNOLOGY: ISSUES AND HYPOTHESES}

Various factors may affect farmers' decision to adopt an innovation. These include, among others, farm size, tenurial status, membership of farmers' organization, level of education, access to critical inputs like irrigation and credit, and subsistence pressure. Other factors like objective and subjective riskiness of the innovation and farmers' perception of the profitability and expected increase in income also affect the adoption decision. This section has two objectives. First, it provides various indicators of adoption. Secondly, it presents a brief description of the theoretical and conceptual framework and sets forth the hypotheses that are to be empirically investigated later in the paper.

\section{Indicators of HYV Adoption}

Following Ahmed (1981) and Lipton (1978), we consider four indicators ${ }^{2}$ of adoption as follows: (a) Crude adoption rate:

(b) Intensity of adoption:

(c) Index of participation.

(d) Propensity to adopt:
It is defined as the ratio of the number of farmers cultivating HYVs to the total number of farmers.

Defined as the percentage of farm area under HYV.

Defined as the product of the crude adoption rate and intensity of adoption.

Defined as the likelihood of a farmer adopting the HYV innovation.

\section{Nature and Direction of Causality, Adoption and Other}

\section{Variables: A priori Reasoning}

Agricultural production in Bangladesh is organized around small family farms with fragmented plots. Socio-economic factors apart, an average Bangladeshi peasant confronts extreme natural constraints imposed by topographic and climatic conditions. Cultivation practices are still basically traditional even though the introduction of new agricultural technology has made steady progress in the last two decades. Average family size is well above five indicating a highly unfavourable land-man ratio given that the average size of holding is small. In such a scenario, survival and food consumption seem to be the only major concern of an average Bangladeshi peasant household.

The analysis of peasant behaviour toward adoption of innovation can be facilitated by referring to the Chayanovian [see Thorner et al. (1966)] and safety-first models. $^{3}$ In the former model, requirement for absolute subsistence (total consumption need) which increases with the growth in family size is the critical determinant of a peasant family's economic activity. A peasant household in such a model is assumed to respond to growing absolute subsistence by, among other things, a greater acquisition of the means of production, primarily land, either by its purchase or by extension of margin. In the safety-first models, a farm household is assumed to ensure survival for itself and, therefore, it wants to avoid the risk of his income or return falling below certain minimum (subsistence) level [Roy (1952), Shahabuddin et al. (1986); Tisdell (1962)]. How the absolute and relative subsistence requirements and other variables are likely to influence the attitude of an average Bangladeshi peasant toward adoption of HYV innovation, is taken up in the remainder of this section.

\section{Absolute and Relative Subsistence Pressure and Adoption}

While absolute subsistence pressure implies total consumption needs for subsistence, relative subsistence requirements are determined relative to the productive capacity of the peasant household. The two variables will have two different types of influence on the farmer's adoption behaviour.

In respect of crude adoption absolute subsistence is likely to have a positive impact on adoption. However, there may be considerable uncertainty about the outcome of adopting the innovation. Under the circumstances, relative subsistence pressure may assume decisive significance. If the farm household is not endowed with enough productive resources in relation to its absolute subsistence, it may not survive a possible disaster. Thus relative subsistence may have a dampening impact on the crude adoption rate.

With the Bangladesh situation militating strongly against increasing the extensive margin of cultivation, the only effective means of raising farm production is through the use of productivity-improving technology. As the required minimum subsistence income increases, as it does with the increase in family size, the intensity of adoption is likely to increase since the subsistence constraint cannot otherwise be

${ }^{3}$ These are not the only possible models. Kautsky (1899); Banaji (1976), for example, sees innovation in agriculture as a flow on from the penetration of industry to country towns. Farmers' cash needs increase so as to purchase farm capital produced by such industry and other dynamic changes occur which make farmers more dependent on the market. In this way they may be subjected to increased risks and the uncertainty elements in the decision-making becomes more important. Neoclassical economists such as Marshall (1890) and Hicks (1946) give little attention to uncertainty in their decision-making models unlike the safety-first models. 
met. It is, therefore, implied by the Chayanovian and safety-first models that intensity of adoption is likely to be positively associated with both variants of subsistence pressure.

\section{Farm Size and HYV Adoption}

A large body of empirical evidence [e.g., Dasgupta (1977), Bhati (1976); Palmer (1976, 1977); Ahmed (1981); Asaduzzaman (1979)] indicate that a higher percentage of larger farmers adopt HYVs compared to smaller farmers. In other words, crude adoption rates seem to be positively associated with farm size. A number of explanations have generally been put forward for such an observed variation in crude adoption rates across farm size. In this respect both demand and supplyside forces may be at work. The households with higher absolute subsistence pressure and lower relative subsistence pressure, as argued above, are likely to experience a stronger demand push for HYV adoption. Larger family size and lower relative subsistence pressure are usually characteristic of larger farm households.

The supply-side factors are also favourable to large farm households. Land of comparable quality is the best index of wealth and is the foundation of rural economic structure. Larger farmers by virtue of their command over a larger slice of land enjoy greater socio-economic power. They are generally identified with the rural ruling elite and are closely identified with the ruling elite at the national level. They also have better access to sources of critical inputs like institutional credit [Alam (1981); Chaudhury and Ghafur (1981); Feder and O'Mara (1981)]. Only one supply-side factor seems to be relatively less abundant or scarce for the larger farmers compared to their smaller counterparts, namely labour, particularly family labour.

These factors have important implications for riskiness and profitability of an innovation for different classes of farmers. The favourable supply-side factors make the HYV technology relatively less risky for the larger farmers compared to the smaller farmers. As Herdt and Dehn (1978, p.192) put it, "several things may contribute to the observed reluctance or inability of operations of the small farm to accept the same HYV which are clearly profitable on large farms. Among those, the risk involved in using an unknown technology may be a primary factor". This follows from fundamentally different risk bearing capacity of large farmers from that of the small farmers. Higher degree of risk attached to HYV cultivation for smaller farmers is partly because of imperfect distribution of the sources of knowledge of the new technology. As Ahmed (1981, p.13) reports, "while bulk of the smaller farmers in Bangladesh rely on indigenous sources of information on the new technology, a higher proportion of larger farmers has better access to government agricultural extension agencies". Furthermore, smaller farmers confront market uncertainty resulting from fluctuations in input and output prices. The working capital requirements associated with the new tchnology are substantially higher. Moreover, smaller farmers may get a lower price for their produce compared to the larger farmers due to the former's lack of storage facilities and inability to hold on to their produce until prices are favourable. These have relevance to the relative profitability for different crops and cropping patterns even though it may be more important for the larger farmers.

Despite a higher degree of risk and uncertainty surrounding their HYV adoption, once adoption takes place, the smaller farmer may be said to have overcome a psychological barrier. In such a situation, the smaller farmers are likely to apply as much effort as possible in the cultivation of HYVs for two reasons: First, they have to make the most of the overhead costs incurred in connection with the collection of information and procurement of critical inputs. Secondly, because they are likely to be better endowed with labour resources, and as the opportunity cost of family labour may not be very high due to incidence of unemployment and underemployment, they are more likely to apply family labour more liberally than those farmers who rely primarily on hired labour. Possibly also smaller farmers are likely to apply more labour to reduce risk. The degree of intensity of adoption may also differ between farmer classes for a further reason. Given supply constraints of various inputs, larger farmers are more likely to concentrate on the riskier crop, growing it on a portion rather than on the entire land area and thereby diversifying their crop portfolio and hence risk. The smaller farmers on the other hand, have very little scope of diversification because of their limited control of land and other resources. Therefore, once adoption takes place and is found to be successful, on the smaller farmers' land, a higher percentage of their land is likely to be allocated to the cultivation of HYVs.

\section{Tenancy and Adoption}

The preceding arguments regarding the likely adoption behaviour of the smaller farmers also apply to that of the tenant farmers who generally own smaller amounts of cultivable land. However, the sharecroppers also confront tenurial insecurity implying tenant eviction almost at will by the owner of the sharecropped land. All these are likely to lead to a lower crude adoption rate among the tenants. ${ }^{4}$ As for the intensity of adoption, it is argued that a tenant farmer may be able to diversify risk of crop failure. However, it is equally true that a tenant farmer with the same level of output will have less for subsistence than an owner farmer ceteris paribus. Furthermore, where the tenant has to bear the entire or a substantial percentage of the costs of cultivation, as is usually the case, diversification if risk of crop failure may have little significance. On the other hand, because of his vulnerable economic position (absolute subsistence pressure), a sharecropper may even be more desperate than an owner farmer to adopt HYV. Therefore, the net effect is difficult to predict a priori. 


\section{Relative Labour Scarcity and Adoption}

Empirical studies [e.g., BPC (Undated); Alauddin and Mujeri (1985)] clearly demonstrate that HYVs require more labour per hectare than the traditional varieties. While labour requirements for HYVs are generally higher, they are much more so in the case of irrigated HYVs. The relative abundance/scarcity of family labour (in relation to land) is likely to affect the farmer's decision to adopt as well as the intensity of adoption. When the farmer is better endowed with labour resource and this labour resource has a low opportunity cost either because of limited opportunities to work outside his land or because the disutility from work is low (low utility from leisure), as may be the case with the smaller farmers, he is more inclined to demonstrate higher intensity of adoption. On the other hand, where relative labour scarcity of family labour exists and the opportunity cost is high, there is likely to be less incentive to innovate. Higher intensity of adoption is unlikely as this will involve employing hired labour in higher amounts thereby reducing profitability of adopting the new technique.

Furthermore, small farms are typically family based while large farms are wage based (Sen 1975). The opportunity cost of labour for small farms using family labour being virtually nil, the application of labour is likely to continue until its marginal product reaches zero or near zero. On the other hand, on larger farms dependent on hired labour, there is likely to be a tendency to equate its marginal product with the wage rate. This has implications for adoption of innovations.

\section{Education and Adoption}

Education is sometimes regarded as a very important factor in agricultural development. Empirical studies [see, for example, Griliches (1964); Schultz (1964); Chaudhri (1979)] demonstrate substantial positive contribution of education in agricultural development. Education can be said to have an innovative, allocative, and efficiency impact as well as a favourable externality (Chaudhri 1979).

The innovative influences lie in the abilities of the educated persons to (i) derive new information; (ii) evaluate costs and benefits; and (iii) establish rapport and therefore access to newly available information.

The allocative effect consists in the ability to select an efficient crop portfolio, new inputs and cultural practices. The efficiency effect implies improvement in the quality of labour (Diwan 1971).

Favourable externality arises from the fact that education lowers communication costs (Tisdell 1982). It might also be argued that greater education in the community results in more ideas and inventiveness. These yield benefits not all of which can be appropriated by the originator. In the case of agricultural innovations, farmers in close contact with an educated farmer can benefit from consultation regarding resource allocation and related issues. One must, however, recognize the importance of the type and "quantity" of education. In many countries education is seen as a stepping stone for rural-urban as well as international migration.

To sum up, let us present in Table 1 the hypotheses that are being tested. Also set out are the definitions of the relevant variables.

Table 1

Hypotheses and Relevant Variables

\begin{tabular}{lclll}
\hline \multirow{2}{*}{ Factors } & \multicolumn{3}{c}{ Influence on Adoption on a priori Grounds } \\
\cline { 2 - 5 } & $\begin{array}{c}\text { Crude Rate } \\
\text { of Adoption of Adoption }\end{array}$ & $\begin{array}{c}\text { Index of } \\
\text { Participation }\end{array}$ & $\begin{array}{c}\text { Propen- } \\
\text { sity to } \\
\text { Adopt }\end{array}$ \\
\hline Farm size & Positive & Negative & Positive & Positive \\
Tenancy & Positive & Positive & Positive & Positive \\
Absolute Subsistence Pressure & Positive & Negative & Unknown & Positive \\
Relative Subsistence Pressure & Negative & Positive & Unknown & Negative \\
Agricultural Worker & Positive & Positive & Positive & Positive \\
Labour Scarcity/Land Abundance Positive & Negative & Unknown & Positive \\
Education & Positive & Positive & Positive & Positive \\
Irrigation & Positive & Positive & Positive & Positive \\
\hline
\end{tabular}

Definition of Variables

Farm Size $\quad$ : Amount of owned or operated land (OWNAREA or OPERA).

Subsistence Pressure : Absolute subsistence pressure (ABSUB) is measured in terms of number of consuming units of male adult equivaterms of number of consuming units of male adult equiva-
lents. Adults are defined as persons of 10 years and over. Female adults and children have been converted into male adult equivalents using conversion factors of 0.90 and 0.50 respectively (cf. Asaduzzaman, 1979) Relative subsistence pressure is defined as the ratio of absolute subsistence pressure to farm size $(\mathrm{ABSUB} / \mathrm{OWNAREA}=$ SUBSIST or ABSUB/OPERA = SUBSIST 1 ).

Agricultural Worker : Number of adult male family members available for agricultural work excluding full-time students (AGWORKER).

Labour Scarcity : Defined as the ratio of agricultural workers to size of owned land (LABSUP = AGWORKER/OWNAREA).

Education : An educational score for each farm household has been defined. On the basis of information on the level of education for each adult member of the household. For each lion for each adult member of the household. For each secondary $=1.00$; above primary and up to secondary $=$ 0.50 ; primary $=0.25$. The aggregate of these scores is the educational score of the household (EDU). A zero score implies that all its adult members are illiterate.

Tenancy Operated land as a percentage of own land (PCOPERA).

Irrigated Area centage area irrigated implies irrigated land as a percentage of operated area (PCIRRI). 


\section{DESCRIPTION OF SURVEY METHOD AND SURVEY AREAS}

The data for this paper are derived from sample surveys in two Bangladeshi villages. The collected data relate mainly to the crop year 1985-86. Employing a direct questionnaire method, we collected data at the farm level with the aid of research investigators. The field work was conducted during the August-October period in 1986. The survey villages of Ekdala in the North-western district of (greater) Rajshahi and South Rampur in the Eastern district of Comilla were selected purposively. We chose them for three reasons: (a) their long tradition with HYV technology; (b) relatively easy access by road or train from the respective district headquarters and the capital city of the country; and (c) their geographic separation and location in different ecological zones.

Geophysically South Rampur belongs to a more frequently flooded and fertile areas of the eastern region of Bangladesh. The village experiences an average rainfall of well over 200 centimetres and is located in the high rainfall zone (BBS 1985). South Rampur is flooded more or less every year and is a flood-prone village in the Surma-Kusiyara flood plain. Ekdala, on the other hand, belongs to the low rainfall area and experiences an average annual rainfall of 120-150 centimetres (BBS 1985). The village is in the dry zone and can be considered drought-prone located in the lower Mohananda and higher part of the Ganges flood plains (BBS 1985). Apart from differences in geophysical characteristics, the two villages differ significantly from one another in terms of (a) pattern of land ownership and distribution; (b) intensity of irrigation; (c) cropping pattern and intensity of cropping and (d) incidence of landlessness [Alam (1984); Saha (1978)]

The year 1985-86 was a fairly normal one for both the villages. It is also worth mentioning that both South Rampur and Ekdala may be geophysically considered to be somewhat typical of many villages in their respective ecological zones. Technologically, however, both the villages are fairly progressive compared to many villages in Bangladesh.

In all, 58 landowning farm households were interviewed in each of the two villages. The samples constituted about 35 percent and 43 percent of the total landowning households in Ekdala and South Rampur respectively. Following the latest agricultural census classification (BBS 1986; see also BBS 1981) three farm categories for Ekdala were defined as: small farms (up to 1 hectare), medium farms (1-3 hectares) and large farms ( 3 hectares and above). The number of Ekdala farmers interviewed in each category were 40,11 and 7 respectively which corresponded to the proportion of each category in the total population of landowners in the village. In South Rampur a slightly different classification was employed as there were rarely any large farmers according to the above classification (cf. Asaduzzaman 1979). For South Rampur the three form categories were defined as:
(1) small (up to 1 hectare); (2) medium (1-2 hectares); and (3) large (2 hectares and above). The number of South Rampur farmers interviewed in small, medium and large farm categories were 35,15 and 8 respectively.

\section{EMPIRICAL RESULTS}

\section{Broad Pattern}

Table 2 provides a broad picture of the extent of HYV adoption in the two study villages. Significant difference can be noticed in regard to the adoption of rabi (dry) season cereals. Whereas all the rabi season rice crop is under HYV in South Rampur, only less than half of the net cropped area is allocated to rabi HYV cereals in Ekdala. If wheat is excluded, only 28 percent of the net cropped area is under HYV boro rice. However, there is little or no difference in the intensity of adoption during the kharif (wet) season. In both the villages, 40 percent of the net cropped area is planted with aman HYV rice. When the gross area cropped with all HYVs is expressed as a percentage of the net cropped area, the contrasting pattern comes into sharper focus. The percentage for South Rampur is more than 60 percent higher than that of Ekdala. Also there is an inter-village difference in the relative share of rabi and kharif HYV areas in (gross) HYV area. For Ekdala, there is no significant difference between the relative shares of rabi and kharif HYV areas. However, for South Rampur, the relative share of boro HYV area is 2.5 times that of aman HYV area.

Information on crude adoption rate, intensity of adoption and index of participation in Ekdala and South Rampur are set out in Table 3. As rice is the dominant crop in Ekdala and it is the only crop in South Rampur, data on the adoption of HYV rice disaggregated by season and by farm size are presented. Several points emerge from a closer examination of the information contained in Table 3.

(1) The crude adoption rate for HYV boro is lower among smaller farmers of Ekdala. It is the highest for the medium farmers followed closely by the large farmers. For aman HYV, it is systematically higher for larger farmers. In South Rampur crude adoption rate for aman HYV increases with the farm size. All the non-adopters are from the small farm category.

(2) For Ekdala, the intensity of adoption of boro HYV is lower for larger farmers. However, there does not seem to be any systematic relationship for aman HYVs in either village.

(3) The index of participation follows a similar pattern as that of intensity for boro HYV in Ekdala. But in both areas for aman HYV, it tends to rise with farm size although not systematically. 
Table 2

Broad Pattern of HYV Adoption in Two Bangladeshi Villages: Ekdala (Rajshahi), and South Rampur(Comilla), $1985-86$

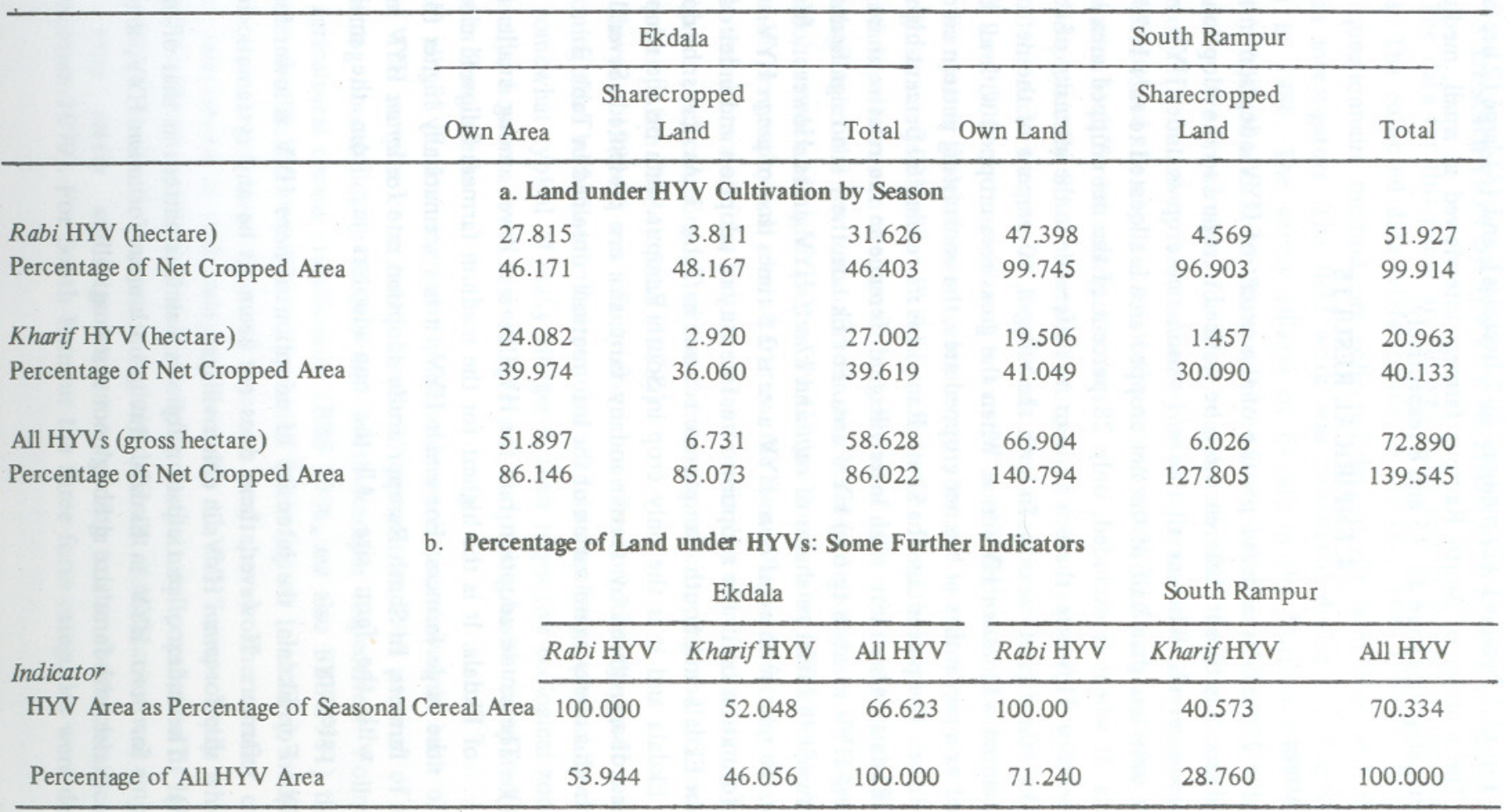

Table 3

Various Indicators of HYV Adoption by Farm Size: Ekdala (Rajshahi) and South Rampur (Comilla), $1985-86$

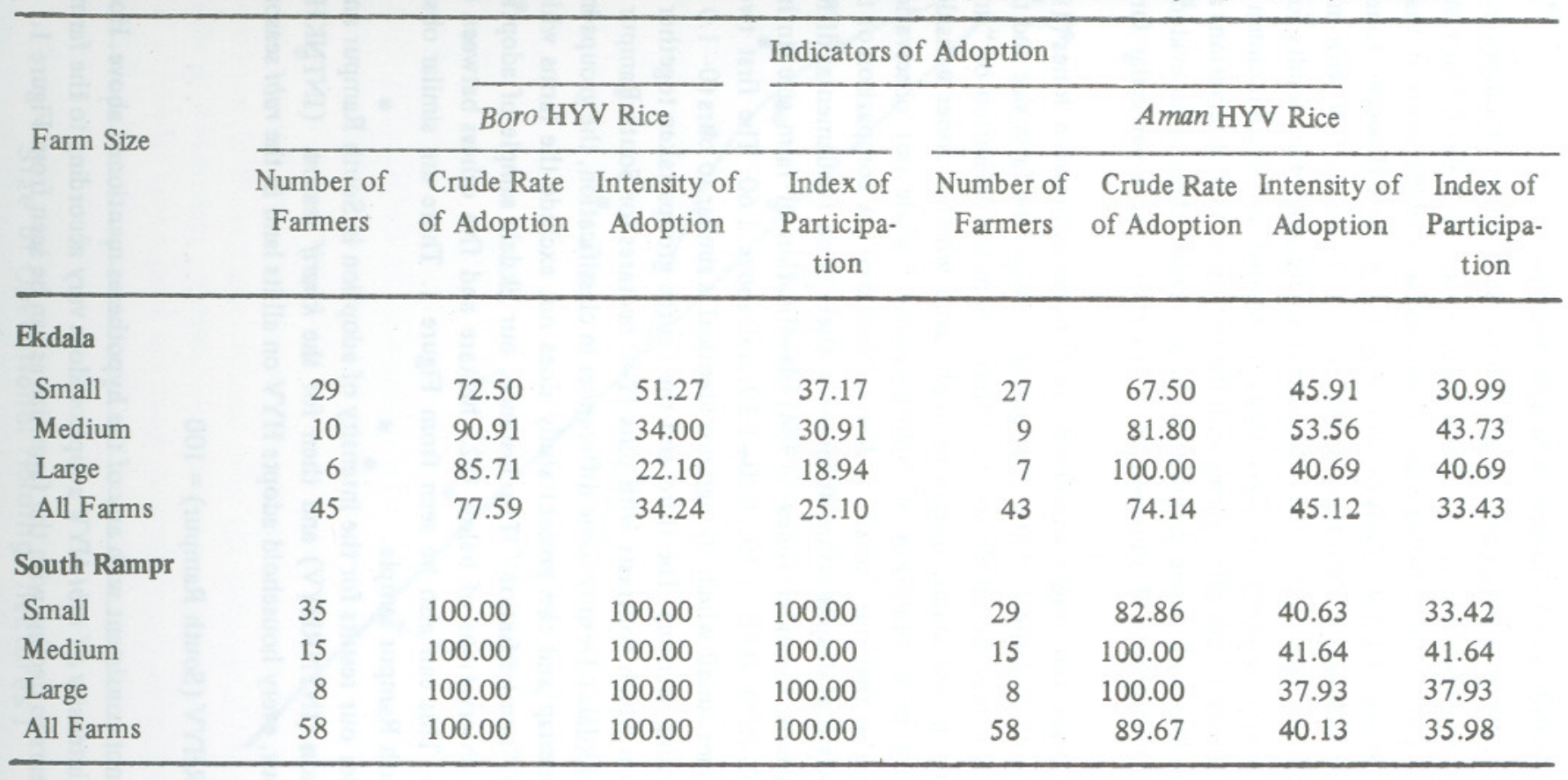




\section{Intensity of adoption and Farm-size: A Simple Analysis}

The objective of this section is to show how the intensity of adoption of HYVs is related to the overall size of farm holdings in our samples. We use farm size as the dependent variable. Ahmed (1981) and Asaduzzaman (1979) contend that the intensity of adoption of HYVs tends to decline with farm size. However, Jones (1984) claims that the intensity of adoption of HYVs tends to fall at first with increase in farm size and then rise so that the relacionship is U-shaped. Our results for Ekdala and South Rampur support the hypothesis of Ahmed and Asaduzzaman in cases where the intensity of adoption varies with the farm size. Our observations are, however, incompatible with Jones' hypothesis. In particular, there is no evidence whatsoever that the intensity of adoption of HYVs rises after a particular farm size is reached.

At this stage one might wonder if the differences between Jones (1984) and the present study in respect of the relationship between the farm size and the intensity of adoption may be attributed to differences in the definition of "small" and "large" farms. In particular, questions might arise whether Jones considers those farms that are in a condition of "immiserisation" while our observations have excluded them so that our "small" is Jones' "medium". A comparison of the classifications shows that despite some differences, there is no fundamental difference in the classifications. Consider Jones (1984) classification of farm size (in hectares): $0-0.39,0.40-0.79,0.80-1.19,1.20-1.59$ and above 1.60 . The first two groups constitute Jones' small which though not identical is similar to ours ( $0-1.0$ hectares, see the preceding section). The third and the fourth groups taken together make up Jones' medium which contrasts with ours (1-2 hectares for South Rampur and 1-3 hectares for Ekdala). Despite some differences in classification, the groups in the two studies do overlap and the present study does not exclude the farms which are in condition of "immiserisation". For instance, our Ekdala sample of adoption farms include five observations of below 0.25 hectare and five others between 0.25 and 0.33 hectare. This can also be seen from Figure 1. There are similar observations form the South Rampur sample.

Consider our results for the intensity of adoption in South Rampur and Ekdala for rabi season (INTNRHYV) and then for the kharif season. (INTNKHYV). In South Rampur, every household adopts HYV on all its land in the rabi season. So

$$
\text { INTNRHYV (South Rampur) }=100
$$

This case is not consistent with any of the hypotheses mentioned above. However, in Ekdala, the intensity of rabi HYV adoption does vary according to the farm size and broadly appears to decline with the farm size as can be seen from Figure 1.

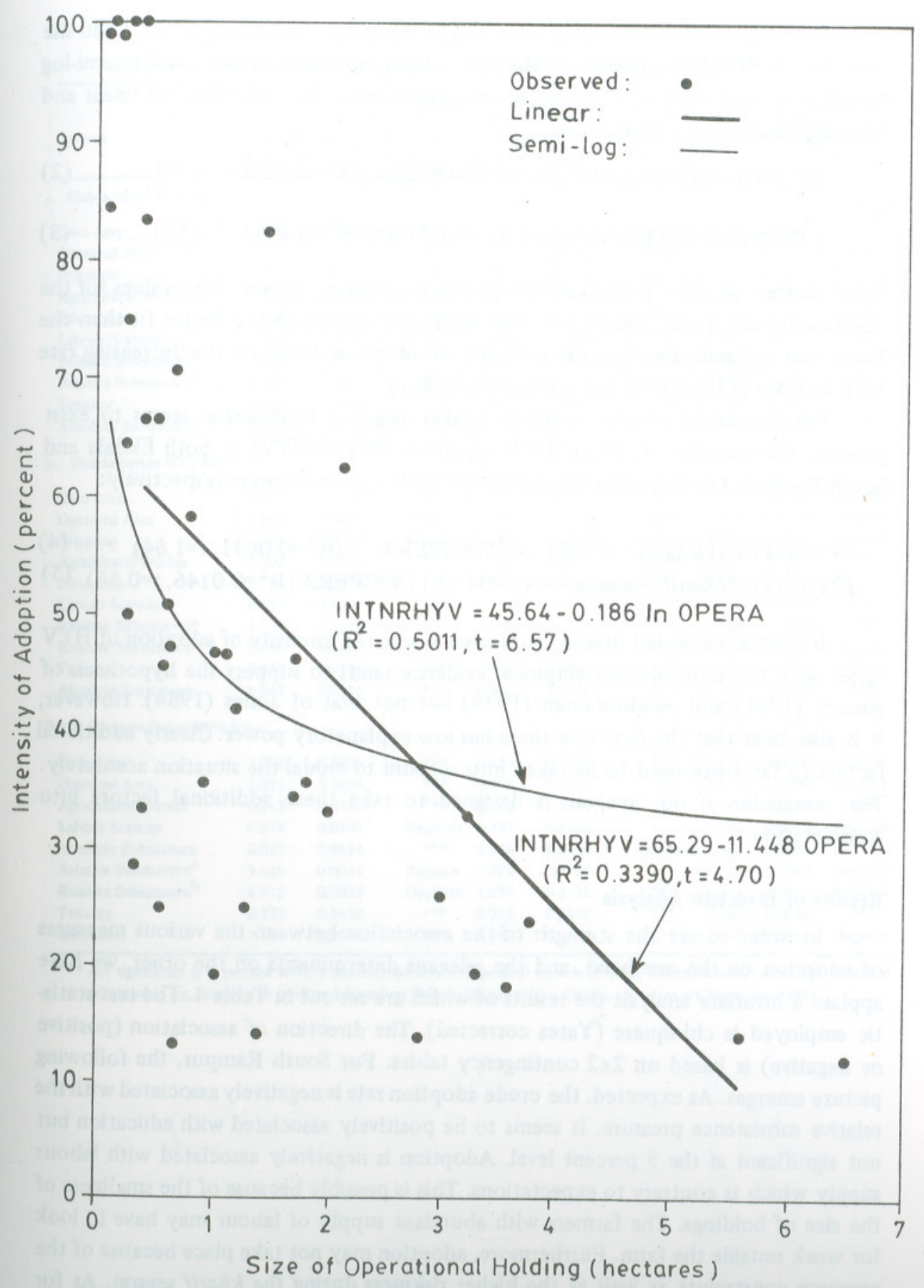

Fig. 1 Relationship between Intensity of Adoption (INTNRHYV) and Size of Operational Farm-holding (OPERA) for Ekdala Sample in the Rabi Season 
To estimate the relationship between the intensity of adoption of HYV and the farm size (OPERA) in Ekdala in the rabi season, we fitted a linear and a semi-log function by least squares to the scatter of observatior.s. The results for the linear and semi-log functions are respectively:

$$
\text { INTNRHYV }(\text { Ekdala })=65.29-11.448 \text { OPERA }\left(R^{2}=0.3390, t=4.70\right) \ldots
$$
and

$$
\operatorname{InINTNRHYV~}(\text { Ekdala })=45.64-0.1860 \operatorname{PERA}\left(\mathrm{R}^{2}=0.5011, \mathrm{t}=6.57\right) \ldots
$$

While neither of these functions have strong explanatory power, the $t$-values for the coefficients are highly significant. The semi-log function gives a better fit than the linear one and indicates that the intensity of adoption decreases at a decreasing rate with increase in the size of the operational holding.

For the kharif season, a much weaker negative relationship seems to exist between the intensity of kharif HYV adoption (INTNKHYV) in both Ekdala and South Rampur. For the linear functions, the least squares fits were respectively:

$$
\begin{aligned}
& \text { INTNKHYV }(\text { Ekdala })=57.005-4.5526 \text { OPERA } \quad\left(R^{2}=0.0631, t=1.64\right) \cdots \\
& \text { INTNKHYV (South Rampur })=43.904-2.1180 \text { OPERA }\left(R^{2}=0.0146, t=0.86\right)
\end{aligned}
$$

It can be concluded that in those cases where the intensity of adoption of HYV varies with the farm-size,our empirical evidence tends to support the hypothesis of Ahmed (1981) and Asaduzzaman (1979) but not that of Jones (1984). However, it is also clear that the farm size alone has low explanatory power. Clearly additional factors to farm-size need to be taken into account to model the situation accurately. The remainder of our analysis is designed to take these additional factors into consideration.

\section{Results of Bivariate Analysis}

In order to see the strength of the association between the various measures of adoption on the one hand, and the relevant determinants on the other, we have applied a bivariate analysis the results of which are set out in Table 4 . The test statistic employed is chi-square (Yates corrected). The direction of association (positive or negative) is based on $2 \times 2$ contingency tables. For South Rampur, the following picture emerges. As expected, the crude adoption rate is negatively associated with the relative subsistence pressure. It seems to be positively associated with education but not significant at the 5 percent level. Adoption is negatively associated with labour supply which is contrary to expectations. This is possibly because of the smallness of the size of holdings. The farmers with abundant supply of labour may have to look for work outside the farm. Furthermore, adoption may not take place because of the resource constraints as well as the higher riskiness during the kharif season. As for

Table 4

Association of Various Indicators of HYV A doption with Different Factors: Results of Bivariate Analysis

\begin{tabular}{|c|c|c|c|c|c|c|c|c|c|}
\hline Own Area & 1.392 & 0.2381 & **** & 5.957 & 0.0147 & Negative & 6.817 & 0.0090 & Positive \\
\hline Operated Area & 2.489 & 0.1147 & $* * *$ & 7.750 & 0.0054 & Negative & 3.125 & 0.0771 & $* * *$ \\
\hline Irrigation & 5.535 & 0.0186 & Positive : & 24.851 & 0.0000 & Positive & 13.363 & 0.0003 & Positive \\
\hline Agricultural Worker & 0.586 & 0.4441 & $* * *$ & 0.000 & 1.0000 & $* * *$ & 0.384 & 0.5356 & $* * *$ \\
\hline Education & 0.316 & 0.5740 & **** & 0.000 & 1.0000 & $* * *$ & 1.548 & 0.2135 & $* * *$ \\
\hline Labour Scarcity & 0.000 & 1.0000 & *** & 3.695 & 0.0546 & $* * *$ & 0.001 & 0.9757 & $* * *$ \\
\hline Relative Subsistence ${ }^{a}$ & 1.454 & 0.2279 & *** & 6.297 & 0.0121 & Positive & 0.000 & 1.0000 & $* * *$ \\
\hline Relative Subsistence ${ }^{\text {b }}$ & 0.239 & 0.6249 & **** & 6.591 & 0.0102 & Positive & 0.596 & 0.4401 & *** \\
\hline Tenancy & 0.000 & 1.0000 & **** & 0.000 & 1.0000 & $* * *$ & 1.949 & 0.1627 & *** \\
\hline Absolute Subsistence & 0.000 & 0.9909 & **** & 0.551 & 0.4578 & **** & 2.423 & 0.1196 & **** \\
\hline \multicolumn{10}{|c|}{. Ekdala ( $\operatorname{aman}$ HYVRice) } \\
\hline Own Area & 2.379 & 0.1230 & $* * *$ & 0.013 & 0.9104 & *** & 15.430 & 0.0001 & Positive \\
\hline Operated Area & 3.886 & 0.0487 & Positive & 0.448 & 0.5033 & $* * *$ & 6.369 & 0.0116 & Positive \\
\hline Irrigation & 11.154 & 0.0008 & Positive & 18.258 & 0.0000 & Positive & 15.058 & 0.0001 & Positive \\
\hline Agricultural Worker & 0.000 & 1.0000 & $* * *$ & 7.778 & 0.0053 & Positive & 1.891 & 0.1691 & $* * *$ \\
\hline Education & 2.716 & 0.0993 & $* * *$ & 0.688 & 0.4069 & *** & 6.461 & 0.0110 & Positive \\
\hline Labour Scarcity & 0.835 & 0.3608 & $* * *$ & 2.751 & 0.0972 & **** & 0.158 & 0.6912 & *** \\
\hline Relative Subsistence ${ }^{a}$ & 1.518 & 0.2180 & $* * *$ & 0.900 & 0.3428 & **** & 0.828 & 0.3628 & $* * *$ \\
\hline Relative Subsistence ${ }^{\mathrm{b}}$ & 2.706 & 0.0999 & $* * *$ & 0.995 & 0.3186 & $* * *$ & 6.836 & 0.0089 & Negative \\
\hline Tenancy & 0.349 & 0.5589 & *** & 0.038 & 0.8448 & $* * *$ & 3.277 & 0.0703 & ${ }^{* * *}$ \\
\hline Absolute Subsistence & 0.043 & 0.8363 & *** & 0.000 & 1.0000 & $* * *$ & 3.706 & 0.0542 & *** \\
\hline \multicolumn{10}{|c|}{ outh Rampur ( $\operatorname{man}$ HYV Rice) } \\
\hline Own Area & 1.072 & 0.3004 & **** & 0.084 & 0.7716 & **** & 19.718 & 0.0000 & Positive \\
\hline Operated Area & 1.072 & 0.3004 & *** & 0.795 & 0.3727 & $* * *$ & 14.681 & 0.0001 & Positive \\
\hline Agricultural Worker & 0.913 & 0.3393 & $* * *$ & 1.540 & 0.2146 & *** & 1.131 & 0.2876 & $* * *$ \\
\hline Labour Scarcity & 4.274 & 0.0387 & Negative & 0.392 & 0.5315 & $* * *$ & 7.154 & 0.0075 & Negative \\
\hline Absolute Subsistence & 0.027 & 0.8694 & $* * *$ & 5.416 & 0.0200 & Negative & 1.466 & 0.2260 & $* * *$ \\
\hline Relative Subsistence" & 9.686 & 0.0019 & Negative & 1.005 & 0.3160 & $* * *$ & 19.023 & 0.0000 & Negative \\
\hline Relative Subsistence ${ }^{b}$ & 8.912 & 0.0028 & Negative & 1.554 & 0.2126 & **** & 15.907 & 0.0001 & Negative \\
\hline Tenancy & 0.372 & 0.5418 & $* * *$ & 0.012 & 0.9139 & *** & 3.466 & 0.0626 & *** \\
\hline Education & 3.604 & 0.0576 & $* * *$ & 1.899 & 0.1682 & $* * *$ & 13.061 & 0.0003 & Negative \\
\hline
\end{tabular}
Indicators of Adoption

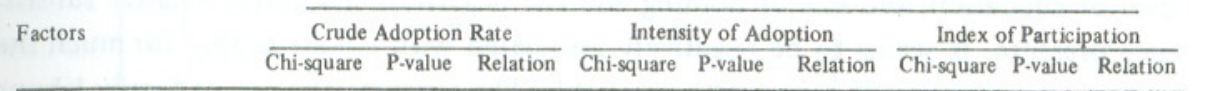

a. Ekdala (boro HYV Rice)

*** not significant at 5 percent level, a absolute subsistence/operated area, $b$ absolute subsistence/own area. The nature of relationship e.g., negative or positive is based on $2 \times 2$ contigency tables. Chi-square values are Yates corrected. 
the intensity of adoption, only absolute subsistence has any statistically significant (positive) association with it. The association with other variables is not statistically significant. As expected, the index of participation is positively associated with the level of education, the size of holding and the negatively associated relative subsistence pressure. It seems to be negatively associated with labour supply for much the same reason mentioned above. Other variables like tenancy, the size of family labour and the absolute subsistence pressure do not seem to have any statistically strong association with the index of participation.

For Ekdala, the crude adoption rate of boro HYV is positively associated with irrigation. Aman HYV crude adoption rate is positively associated with the size of operational holding and the irrigated area. The intensity of boro HYV adoption is positively associated with irrigation, negatively associated with the size of holding and the relative subsistence pressure. As for the index of participation, it is positively associated with both farm size and irrigated area. All these findings are consistent with $a$, yriori expectations. The crude adoption rate of aman $\mathrm{HYV}$ is positively associated with the farm size and irrigation. Significant positive association exists between the intensity of adoption, percent area irrigated and the educational score. The index of participation is negatively associated with the relative subsistence pressure and positively associated with irrigation, education and the size of holding.

So far the hypotheses regarding the effects of various factors have been tested using the bivariate technique of analysis. Because of this, the pure effects of different variables are difficult to ascertain and are likely to contain the effects of other factors as well. For instance, as argued earlier, subsistence pressure may be a critical factor in determining the observed pattern of adoption whenever farm households are classified according to certain criterion. Furthermore, in a $2 \times 2$ contingency table (with one degree of freedom) the requirement of any cell with no fewer than 5 expected frequencies could not always be satisfied. As Leabo (1972, p.535) suggests, ".... . even though the expected frequencies are below the requirement, the usefulness of the test may not be destroyed. The results do become inexact though and may cast doubt on the decision". To investigate the empirical relationships involving various indicators of adoption and other variables, we turn to multivariate analysis in the remainder of this section.

\section{Intensity of Adoption: Multivariate Analysis}

In order to investigate empirically possible determinants of the intensity of HYV adoption, we employ least squares regression analysis. The estimated regression equations are set out in Table 5. A number of regression equations were estimated but the 'best' ones are reported. These are based on the criteria which the BMDP P9R programme employs to select the 'best' one from all possible subsets of regression (see Dixon 1983): Among all the possible determinants of the intensity of boro HYV 
adoption in Ekdala, farm size (both operational and owned), education and percentage area under irrigation seem to be the most important ones. All the coefficients have expected signs and are highly significant. The coefficient of the irrigation variable seems to be the most important followed by farm size and education. Both in terms of explanatory power and statistical significance as indicated by adjusted $R^{2}$ and the $F$-ratio, the overall fit can be considered good.

We estimated a similar equation for intensity of adoption of aman HYV adoption in Ekdala. The overall fit is not good in terms of explanatory power even though the $F$-ratio is significant at the 1 percent level. All the coefficients are of expected sign and possess statistical significance at the 5 percent level. The tenancy variable seems to have a negative impact on the intensity of adoption. Furthermore, the percentage area irrigated has also a significantly jpositive impact on the intensity of aman HYV adoption even though it is primarily a rainfed crop. This is probably because Ekdala being located in the dry zone suffers considerably from uncertainty and inadequacy of precipitation. Under such circumstances, farmers may need to provide supplementary irrigation for aman HYV cultivation. Those without access to irrigation are unlikely to cultivate aman HYV and even if they do, the intensity is unlikely to increase. This is because, as gathered from field observations, in the event of an inadequate and untimely rainfall aman HYV yields can fall below those of the traditional varieties.

For South Rampur the determinants of the intensity of aman HYV are different from the ones in Ekdala. Only the subsistence pressure and labour supply enters the best possible subset of regression. While the coefficient of the former variable has the expected sign, that of the latter does not. The explanatory power of the equation is poor even though the overall $F$-ratio is highly significant.

\section{Propensity of HYV Adoption: Logit Analysis}

We now use a logit analysis to explain the probability of a farmer adopting HYV. The dependent variable is dichotomous in that it assumes a $(1,0)$ value, 1 for adoption and 0 for non-adoption. We do not describe the method in detail here but it can be found in Goldfeld and Quandt (1972); Theil (1971) and Kmenta (1971). ${ }^{5}$ We have used the BMDP PLR programme (Dixon 1983) to estimate propensity functions. The results, disaggregated by season and by region are set out in Table 6 .

Initially we included all the variables considered relevant on a priori grounds. As expected, the propensity to adopt boro HYV is positively associated with the size of holding. However, the coefficients of all other variables lack statistical significance. Another set of regression estimates were made using the size of irrigated $(1971)$.

${ }^{5}$ This method has been widely used in the biological sciences. See, for example, Finney

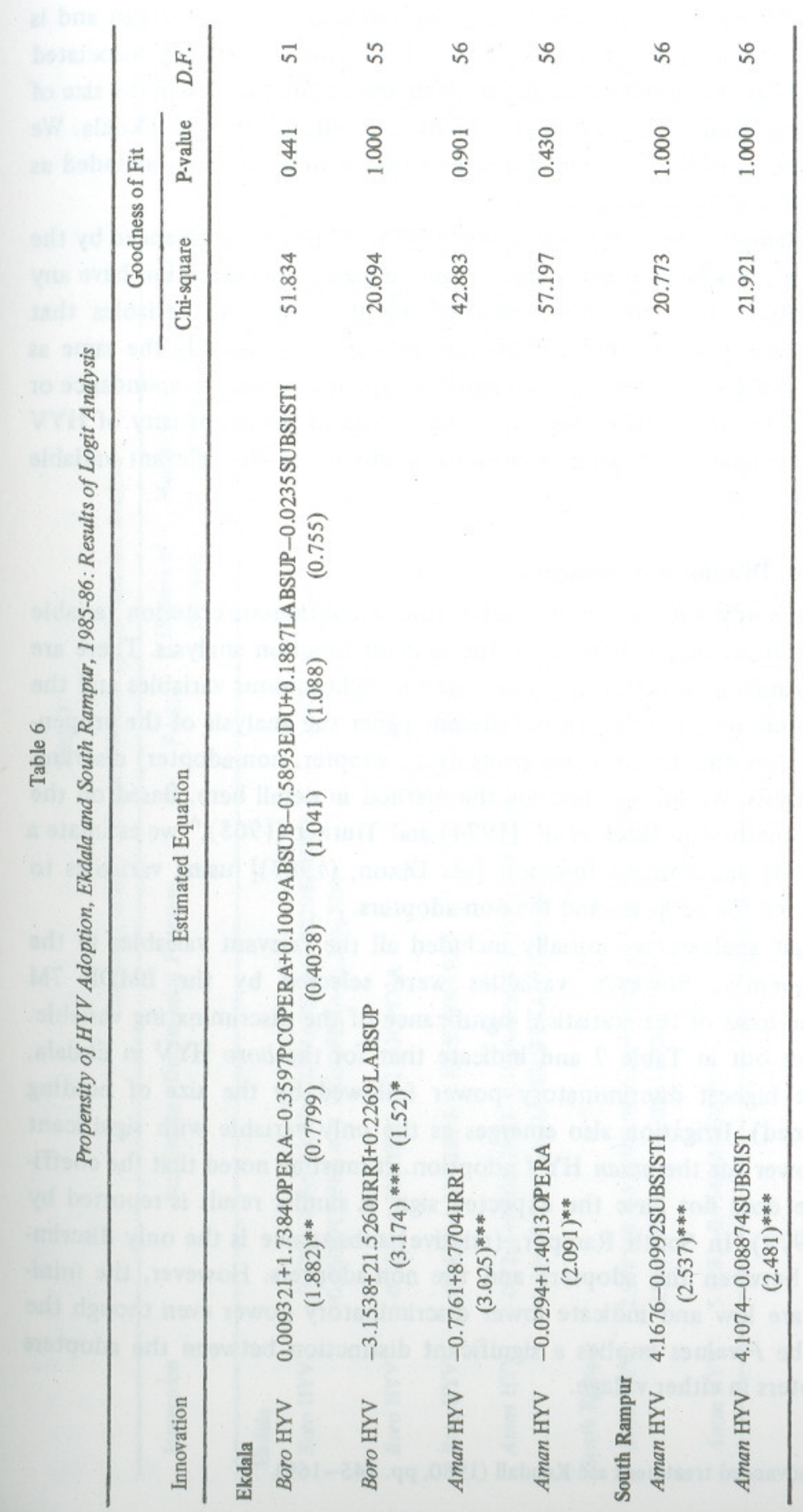


area and other variables. The coefficient of irrigation has the expected sign and is highly significant. The propensity to adopt boro HYV is also positively associated with the supply of family labour. During the aman season, irrigation and the size of holding seem to significantly influence the decision to adopt HYV in Ekdala. We tried with all other variables but none appeared to be significant when included as explanatory variables in the same equation.

For South Rampur, the likelihood of aman HYV adoption is influenced by the relative subsistence pressure. Neither farm size, nor tenancy nor education have any significant association with the propensity to adopt. Thus, the variables that influence the decision to adopt HYVs in one village are not necessarily the same as those in another. For Ekdala farm size, irrigated area and the relative abundance or the scarcity of labour emerge as important determinants of the propensity of HYV adoption while the relative subsistence pressure seems to be the relevant variable for South Rampur.

\section{Adoption of HYVs: Discriminant Analysis}

A prediction study with a nominal rather than a continuous criterion variable calls for a statistical technique known as discriminant function analysis. There are two types of discriminant function analysis: one for dichotomous variables and the other for polychotomous variables. In the present paper the analysis of the propensity to adopt involves the use of a two-group (e.g., adopter, non-adopter) discriminant function analysis. We do not describe the method in detail here. Based on the discussion of the method in Huck et al. (1974) and Tintner (1965), ${ }^{6}$ we estimate a linear (standardized) discriminant function [see Dixon, (1983)] using variables to discriminate between the adopters and the non-adopters.

As with logit analysis, we initially included all the relevant variables in the function. Subsequently, however, variables were selected by the BMDP 7M programme on the basis of the statistical significance of the discriminating variable. The results are set out in Table 7 and indicate that for the boro HYV in Ekdala, irrigation has the highest discriminatory power followed by the size of holding (operated or owned). Irrigation also emerges as the only variable with significant discriminatory power for the aman HYV adoption. It must be noted that the coefficient of farm size does not have the expected sign. A similar result is reported by Asaduzzaman (1979). In South Rampur, (relative) subsistence is the only discriminatory variable between the adopters and the non-adopters. However, the minimum $D^{2}$ values are low and indicate lower discriminatory power even though the significance of the $F$-values implies a significant distinction between the adopters and the non-adopters in either village. 


\section{CONCLUDING REMARKS}

The above analysis has identified factors that affect farm-level adoption of HYV technology in Bangladesh. Employing bivariate and multivariate techniques of analysis and utilizing primary data from two different villages, it has been found that the degree of access to irrigation emerges as the key determinant of the HYV adoption both within and between the villages. All the indicators of adoption, crude adoption rate, the intensity of adoption, the index of participation and the propensity to adopt are significantly influenced by irrigation variable. Other important determinants are farm size, labour scarcity and relative subsistence pressure.

Significant differences between villages exist in the adoption of technology during the dry season. There is 100 percent crude adoption rate HYVs as well as 100 percent intensity of adoption by every farm in South Rampur during the dry season which contrasts with the picture at Ekdala. However, little difference exists in both the measures of adoption of HYVs during the rainy season. It needs to be pointed out that in Ekdala primarily those farmers who have access to irrigation adopt HYVs in the rainy season so that in case of inadequate and uncertain rainfall supplementary irrigation can be arranged. Significant differences between villages exist in the adoption of technology during the dry season. In South Rampur, since everyone irrigates, the significance of irrigation does not show up from statistical analysis. Less than 100 percent crude adoption rate and a little more than 40 percent intensity of adoption of rainy season HYVs in South Rampur is due to the fact that the present HYVs are insufficiently flood-resistant. The adoption of HYVs under flood-prone conditions is a more risky proposition than under assured source of irrigation during the dry season. Nor are they very drought-resistant, as is evident from their adoption in the drought-prone village of Ekdala. In case of a severe flood or a drought, the yields of these varieties may fall below those of the traditional varieties. Under the present circumstances, it is unlikely that for the rainy season, area under HYV area will increase much further.

Using simple analysis and recent data, we found some empirical support for the hypothesis of Ahmed (1981) and Asaduzzaman (1979) that the intensity of adoption of HYV tends to fall with farm size but our observations were incompatible with the hypothesis of Jones (1984). It was also apparent that farm size alone is an inadequate explanatory variable of the intensity of $H Y V$ adoption, even though it has some explanatory power. Additional determining factors such as those highlighted in this paper also need to be taken into account. The problem of correlation between variables, however, exists. Access to irrigation is more probable for example as farm size increases and variables such as the education level tend to be positively correlated with the farm size.

The results indicate a tendency for crude rates of adoption to rise with the farm-size but for the intensity of adoption to fall with the farm size. While the intensity of adoption did not fall in all cases with the farm size (consider South Rampur for the rabi season), there was no evidence of its rising with the farm size even for large-sized farms. Note also that the relationship between the intensity of adoption of HYVs and the farm size is not too invariant between districts and seasons. We should also be aware of the possibility that it may alter, over time, for example, as the diffusion of new HYVs take place. Such variations need to be captured by the dynamic analysis and are not apparent from the static cross-sectional analysis used here and as used by many other economists. Nevertheless, our analysis does throw some light on the patterns and the determinants of adoption of HYVs in Bangladesh.

\section{REFERENCES}

Ahmed, I. (1981). Technological Change and Agrarian Structure: A Study of Bangladesh. Geneva: International Labour Office.

Alam, M. (1984). Capital Accumulation and Agrarian Structure in Bangladesh: A Study on Tubewell Irrigated Villages of Rajshahi and Comilla. Dhaka: Dhaka University, Centre for Social Studies.

Alam, M. F. (1981). "Cost of Credit from Institutional Sources in Banglailesh". Bangladesh Journal of Agricultural Economics. Vol. 4, No. 2. pp. 102-112.

Alauddin, M., and M. K. Mujeri. (1985). "Employment and Productivity Growth in Bangladesh Agriculture: An Inter-District Analysis". Marga. Vol. 8, No. 1. pp. 50-72.

Alauddin, M., and C. A. Tisdell (1986). "Market Analysis, Technical Change and Income Distribution in Semi-Subsistence Economies: The Case of Bangladesh". Agricultural Economics. Journal of the International Association of Agricultural Economists. Vol. 1, No. 1.pp. 1-18.

Alauddin, M., and C. A. Tisdell (1987). "Trends, Projections and Sustainability of Bangladeshi Food Production: An Alternative Viewpoint". Food Policy. Vol. 12, No. 4. pp. 318-331.

Asaduzzaman, M. (1979). "Adoption of HYV Rice in Bangladesh". Bangladesh Development Studies. Vol. 7, No. 3. pp. 23-52.

Banaji, J. (1976). "Summary of Selected Parts of Kautsky's The Agrarian Question". Economics and Society. Vol. 5, No. 1. pp. 2-49.

Bhati, U. N. (1976). Some Social and Economic Aspects of the Introduction of New Varieties of Paddy in Malaysia: A Village Case Study. Geneva: United Nations Research Institute of Social Development.

BBS (1981). Report on the Agricultural Census of Bangladesh 1977 (National Volume). Dhaka: Bangladesh Bureau of Statistics. 
BBS (1985). 1984-85 Statistical Year Book of Bangladesh. Dhaka: Bangladesh Bureau of Statistics.

BBS (1986). The Bangladesh Census of Agriculture and Livestock; 1983-84: Structure of Agricultural Holdings and Livestock Population. Dhaka: Bangladesh Bureau of Statistics. Volume 1.

BPC (n.d). "A Study on All Agricultural Crops". Second Plan/Perspective Plan Study Report Series. Dhaka: Bangladesh Planning Commission.

Chaudhri, D. P. (1979). Education, Innovation and Agricultural Development. London: Croom Helm.

Chaudhry, M. G. (1982). "Green Revolution and Redistribution of Rural Incomes: Pakistan's Experience”. Pakistan Development Review. Vol. XXI, No. 3. pp. 173-205.

Chaudhry, M. G. (1983). "Green Revolution and Redistribution of Rural Incomes: Pakistan's Experience - A Reply”. Pakistan Development Review. Vol. XXII, No. 2. pp. 117-124.

Chaudhury, R. H., and A. Ghafur (1981). "Rural Credit in Bangladesh". Bangladesh Journal of Political Economy. Vol. 5. pp. 287-292.

Dasgupta, B. (1977). Agrarian Change and the New Technology in India. Geneva: United Nations Research Institute of Social Development.

Diwan, R. K. (1971). "Impact of Education on Labour Efficiency". Applied Economics. Vol. 3, No. 2. pp. 127-135.

Dixon, W. J. (1983). BMDP Statistical Software. Los Angeles: University of California Press.

Feder, G., and G. T. O’Mara (1981). "Farm Size and the Diffusion of Green Revolution Technology". Economic Development and Cultural Change. Vol. 30, No. 1. pp. 59-76.

Finney, D. J. (1971). Probit Analysis. Cambridge: Cambridge University Press.

Frankel, F. R. (1971). India's Green Revolution: Economic Gains and Political Costs. Princeton, N. J.: Princeton University Press.

Goldfeld, S. M., and R. E. Quandt (1972). Nonlinear Methods in Econometrics. Amsterdam: North Holland Publishing Company.

Griffin, K. B. (1979). The Political Economy of Agrarian Change: An Essay on the Green Revolution London: Macmillan.

Griliches, Z. (1964). "Research Expenditure, Education and the Aggregate Agricultural Production Function". American Economic Review. Vol. 54, No. 6. pp. 961-974.

Hayami, Y., and R. W. Herdt (1977). "Market Price Effects of Technological Change on Income Distribution in Semisubsistence Agriculture". American Journal of Agricultural Economics. Vol. 59, No. 2. pp. 245-256.

Hayami, Y., and M. Kikuchi (1981). Asian Village Economy at the Crossroads. Tokyo: University of Tokyo Press.
Hayami, Y., and V. W. Ruttan (1984). "The Green Revolution: Inducement and Distribution”. Pakistan Development Review. Vol. XXIII, No. 1. pp. 37-63.

Hayami, Y., and V. W. Ruttan (1985). Agricultural Development: An International Perspective. Baltimore: The Johns Hopkins University Press.

Herdt, R. W., and M. M. Dehn (1978). "Insurance to Small Farmers to Encourage Innovation". Bangladesh Development Studies. Vol. 6, No. 2. pp. 191-200.

Hicks, J. R. (1946). Value and Capital. London: Oxford University Press.

Huck, S. W., W. H. Cormier and W. G. Bounds (1974). Reading Statistics and Research. New York: Harper and Row Publishers.

Jones, S. (1984). "Agrarian Structure and Agricultural Innovations in Bangladesh: Panimara Village, Dhaka District”. In Tim P. Blyss-Smith and Sudhir Wanmali (eds.), Understanding Green Revolutions. Agrarian Change and Development Planning in South Asia. Cambridge: Cambridge University Press. pp. 194-211.

Kautsky, K. (1899). Die Agrafare. Stuttgart.

Kendall, M. G. (1980). Multivariate Analysis. London: Charles Griffin and Co.

Khan, M. H. (1983). "Green Revolution and Redistribution of Rural Incomes: Pakistan's Experience - A Comment". Pakistan Development Review. Vol. XXII, No. 1. pp. 47-56.

Kmenta, J. (1971). Elements of Econometrics. New York: Macmillan. Leabo, D. A. (1972). Basic Statistics. Homewood Ill.: Richard D. Irwin.

Lipton, M. (1978). "Inter-Farm, Inter-Regional and Farm - Non-Farm Income Distribution: The Impact of New Cereal Varieties". World Development. Vol. 6, No. 3. pp. 319-337.

Marshall, A. (1890). Principles of Economics. 1st Edition. London: Macmillan.

Palmer, I. (1976). The New Rice in Asia: Conclusions from Four Country Studies. Geneva: United Nations Research Institute of Social Development.

Palmer, I. (1977). The New Rice in Indonesia. Geneva: United Nations Research Institute of Social Development.

Pearse, A. (1980). Seeds of Plenty, Seeds of Want. Oxford: Clarendon Press.

Prahaldachar, M. (1983). "Income Distribution Effects of the Green Revolution in India: A Review of Empirical Evidence". World Development. Vol. 11, No. 11, pp. 927-944.

Rahman, A. (1981). “Adoption of New Technology in Bangladesh: Testing Some Hypotheses". In W. Mahmud (ed.), Development Issues in an Agrarian Economy: Bangladesh. Dhaka: Centre for Administrative Studies. pp. 55-77.

Rahman, R. I. (1983). "Adoption of HYV: Role of Availability and the Supplyside Problems”. Bangladesh Development Studies. Vol. 11, No. 4. pp. 61-75.

Roy, A. D. (1952). "Safety First and Holding of Assets". Econometrica. Vol. 20, No. 3. pp. 431-449.

Saha, B. K. (1978). Socio-Economic Effects of Technological Change in Bangladesh Agriculture: A Study of Two Villages in Bangladesh. Unpublished M. Phil Thesis. Rajshahi: Rajshahi University. 
Schultz, T. W. (1964). Transforming Traditional Agriculture. New Haven, Conn.. Yale University Press.

Sen, A. K. (1975). Employment, Technology and Development. Oxford: Clarendon Press.

Shahabuddin, Q., S. Mostelman and D. Feeny (1986). "Peasant Behaviour Towards Risk and Socio-Economic and Structural Characteristics of Farm Households in Bangladesh". Oxford Economic Papers. Vol. 38, No. 1. pp. 122-130.

Theil, H. (1971). Principles of Econometrics. New York: John Wiley and Sons. Thorner, D., B. Kerblay and R. E. F. Smith (eds.) (1966). A. V. Chayanov on the Theory of Peasant Economy. Homewood Ill.: Richard D. Irwin. Tintner, G. (1965). Econometrics. New York: John Wiley and Sons. Tisdell, C. A. (1962). "Decision Making and the Probability of Loss". Australian Economic Papers. Vol. 1, No. 1.pp. 109-118. Tisdell, C. A. (1982). Microeconomics of Markets. Brisbane: John Wiley and Sons. 